13

\title{
Ионная модификация автоэмиссионных свойств алмазографитовых пленочных структур
}

\author{
(C) P.К. Яфраров
}

Саратовский филиал Института радиотехники и электроники им. В.А. Котельникова РАН, 410019 Саратов, Россия

e-mail: pirpc@yandex.ru

(Поступило в Редакцию 7 июня 2017 г.)

\begin{abstract}
Изучены закономерности изменения структурно-фазовых, морфологических и автоэмиссионных характеристик нанокомпозитных алмазографитовых пленочных структур, полученных в микроволновой плазме паров этанола, в зависимости от дозы облучении ионами азота с энергией $20 \mathrm{keV}$. Установлено, что при малых дозах облучения морфологические параметры алмазографитовых структур практически не отличаются от параметров необлученных образцов. В отличие от этого автоэмиссионные свойства претерпевают существенные изменения. Причем повышение максимальных плотностей автоэмиссионных токов достигается при повышении порогов возбуждения автоэмиссии. Обнаружены оптимальные дозы ионной имплантации азота, при которых максимальные плотности автоэмиссионных токов возрастают по сравнению с необлученными структурами более, чем в 5 раз. Рассмотрены физико-химические механизмы, ответственные за модификацию поверхностных и приповерхностных свойств алмазографитовых структур в зависимости от дозы ионного облучения.
\end{abstract}

DOI: 10.21883/JTF.2018.01.45496.2374

\section{Введение}

Для создания сильноточных автокатодов, которые могут быть использованы взамен термокатодов в мощных СВЧ ЭВП, наиболее перспективными в настоящее время считаются металлические острия и/или матрицы острий, а также различные наноуглеродные структуры $[1,2]$. Перспективность металлических автокатодов обусловлена характерным свойством металлов, имеющих наиболее высокие концентрации свободных электронов и, как следствие, высокие предельные плотности автоэмиссионных токов. Туннельные токи из металлов хорошо описываются законом Фаулера-Нордгейма и, согласно расчетам, могут достигать $10^{8}-10^{10} \mathrm{~A} / \mathrm{cm}^{2}$. Перспективность наноуглеродных материалов обусловлена их устойчивостью к бомбардировке ионами остаточных газов, имеющих место в приборах, работающих в условиях технического вакуума и высоковольтного питания. Кроме того, наноуглеродные материалы при определенных структурных модификациях, характерных для алмазного типа гибридизации связей валентных электронов или углеродных нанотрубок с графитовым типом структуры, имеют более низкую работу выхода электронов [3]. Это уменьшает энергетическую нагрузку на материал автокатодов и позволяет получать высокие плотности автоэмиссионных токов. Так, в работах Аргонской национальной лаборатории, США, показано, что нанокристаллические алмазные покрытия наноострий и пленки, полученные с использованием неравновесной микроволновой плазмы способны обеспечивать чрезвычайно высокую плотность тока (до 60-100 $\mu \mathrm{A}$ на острие!) и стабильность.

Однако на пути практического использования сильноточных автокатодов имеется ряд принципиальных труд- ностей. Они связаны с тем, что управление прозрачностью потенциальных барьеров, определяющих порог начала и плотности токов автоэмиссии электронов из твердого тела в вакуум, осуществляется в основном за счет высоких напряженностей внешних электрических полей $\sim 10^{6-7} \mathrm{~V} / \mathrm{cm}$. Эти напряженности весьма близки к значениям электрической прочности большинства известных в природе материалов (напряженность поля лавинного пробоя кристаллического кремния составляет, например, всего $\left.3 \cdot 10^{5} \mathrm{~V} / \mathrm{cm}\right)$. Другими важными факторами являются статистическая неоднородность рельефа поверхности, с которой происходит основная эмиссия, и ее малая площадь (порядка одного процента). Все это приводит к высокой неоднородности автоэмиссии по поверхности катодов, которая вызывает в условиях больших локальных джоулевых перегревов эмиссионных центров неоднородную деструкцию поверхности и их ускоренное разрушение. Поэтому проблема стабильности и долговечности сильноточных автокатодов, несмотря на интенсивные исследования ученых всего мира, остается одной из важнейших для эмиссионной электроники.

Цель работы - исследование возможности увеличения предельных плотностей автоэмиссионных токов для увеличения ресурса эксплуатации полевых источников электронов на основе нанокомпозиционных алмазографитовых структур.

\section{1. Методика и результаты экспериментов}

Получение нанокомпозиционных алмазографитовых структур на поликоровых подложках осуществлялось с 

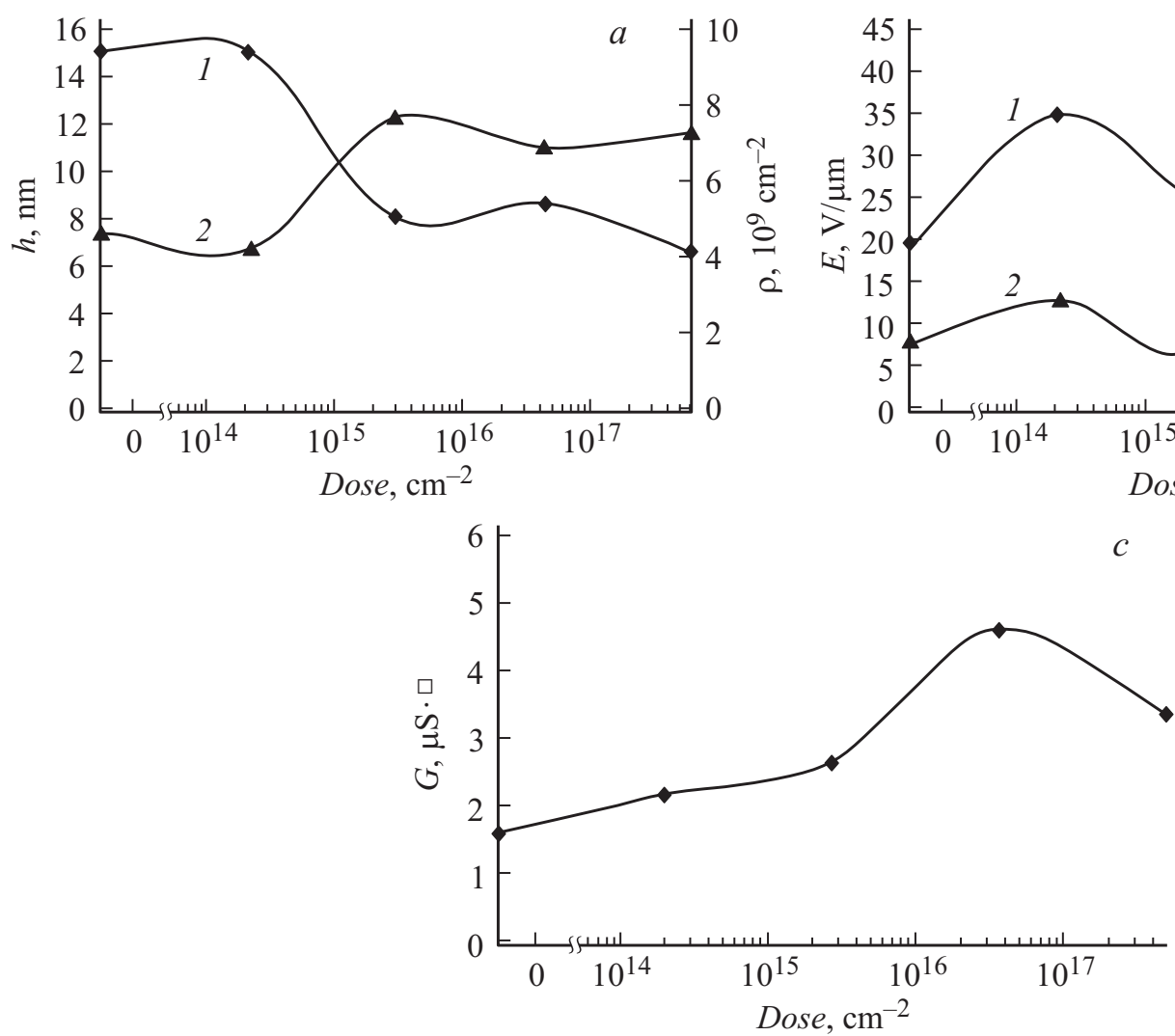

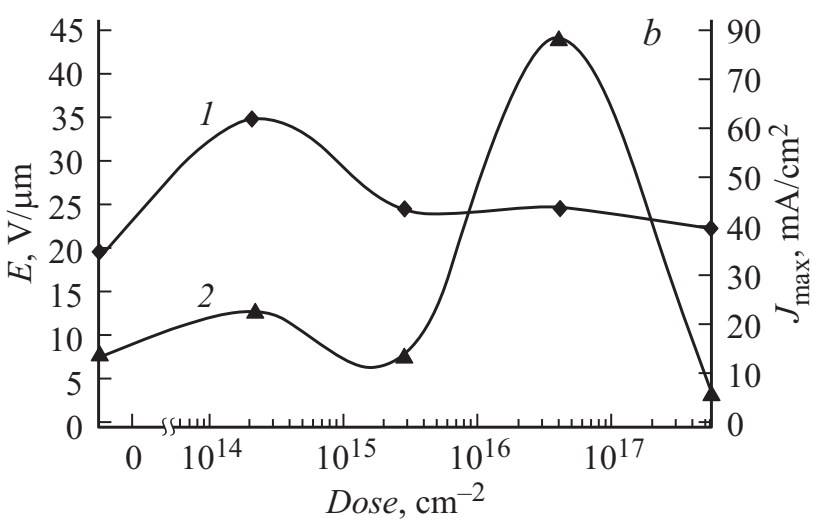

$c$

Рис. 1. Зависимости высот (1) и поверхностных плотностей (2) выступов $(a)$, порогов возбуждения (1) и максимальных плотностей токов автоэмиссии $(2)(b)$ и проводиомсти $(c)$ на алмазографитовой пленке от дозы имплантированного азота.

использованием микроволнового газового разряда паров этанола на частоте $2.45 \mathrm{GHz}[4]$. СВЧ мощность, вводимая в источник плазмы, составляла $250 \mathrm{~W}$. Процесс осуществлялся в условиях малой адсорбции при температуре подложки $350^{\circ} \mathrm{C}$ и давлении паров этанола около $0.05 \mathrm{~Pa}$. Потенциал смещения на подложкодержателях в процессах осаждения углеродных покрытий составлял $300 \mathrm{~V}$. Полученные наноалмазографитовые покрытия толщиной $0.1-0.2 \mu \mathrm{m}$ подвергались облучению ионами азота с энергией $20 \mathrm{keV}$ на установке ИЛУ-3 при комнатной температуре. Облучение образцов проведено при четырех значениях дозы ионов: $1 \cdot 10^{14} ; 3 \cdot 10^{15}$; $3 \cdot 10^{16} ; 3 \cdot 10^{17} \mathrm{~cm}^{-2}$. Плотность ионного тока составляла $0.5 \mu \mathrm{A} / \mathrm{cm}^{2}$ для минимальной дозы и $3 \mu \mathrm{A} / \mathrm{cm}^{2}$ для всех остальных доз. Для анализа морфологии и фазового состава ионно-имплантированных алмазографитовых нанокомпозитов были использованы методы атомно-силовой и конфокальной рамановской микроскопии/спектроскопии. Рамановская спектроскопия благодаря наличию в спектре рамановского рассеяния характерных линий, соответствующих полосам $G$ при $1585 \mathrm{~cm}^{-1}$ и $D$ при $1350 \mathrm{~cm}^{-1}$ рассеяния на $s p^{2}$ - и $s p^{3}$-связях углерода, позволила определить закономерности структурнофазовых превращений в углеродных материалах в зависимости от режимов их получения и ионно-лучевой обработки. Наноморфология поверхностей изучалась с помощью сканирующего атомно-силового микроскопа
(ACM) P4-SPM-MDT. В качестве зонда использовались стандартные кремниевые кантилеверы CSG10 пирамидальной формы с радиусом закругления $10 \mathrm{~nm}$ и жесткостью $0.1 \mathrm{~N} / \mathrm{m}$. Поле сканирования составляло $3 \times 3 \mu \mathrm{m}$.

Исследования автоэмиссионных свойств осуществлялись в условиях высокого вакуума $\left(10^{-5} \mathrm{~Pa}\right)$ на диодной структуре, способной изменять расстояние между электродами с точностью до $1 \mu \mathrm{m}$. Диаметр рабочей поверхности анода, изготовленного из углеродного материала МПГ-6, составлял $3 \mathrm{~mm}$.

На рис. 1 приведены зависимости от дозы имплантации морфологических и автоэмиссионных характеристик, а также поверхностной проводимости полученных алмазографитовых пленочных структур. Из рис. 1, $a$ видно, что при малых дозах ионного облучения морфологические параметры пленочной структуры (высоты выступов и их поверхностные плотности) практически не изменяются по сравнению с необлученными образцами. В то же время автоэмиссионные характеристики претерпевают существенные изменения (рис. $1, b)$. Порог возбуждения автоэмиссии увеличивается от 19.5 до $35 \mathrm{~V} / \mu \mathrm{m}$, а максимальные плотности токов от 14.3 до $22.9 \mathrm{~mA} / \mathrm{cm}^{2}$. В интервале средних $\left(3 \cdot 10^{15}-3 \cdot 10^{16} \mathrm{~cm}^{-2}\right)$ и больших $\left(3 \cdot 10^{17} \mathrm{~cm}^{-2}\right)$ доз облучения высоты выступов по сравнению с необлученными образцами и облученными с малыми дозами уменышаются в два раза, а поверхностные плотности 

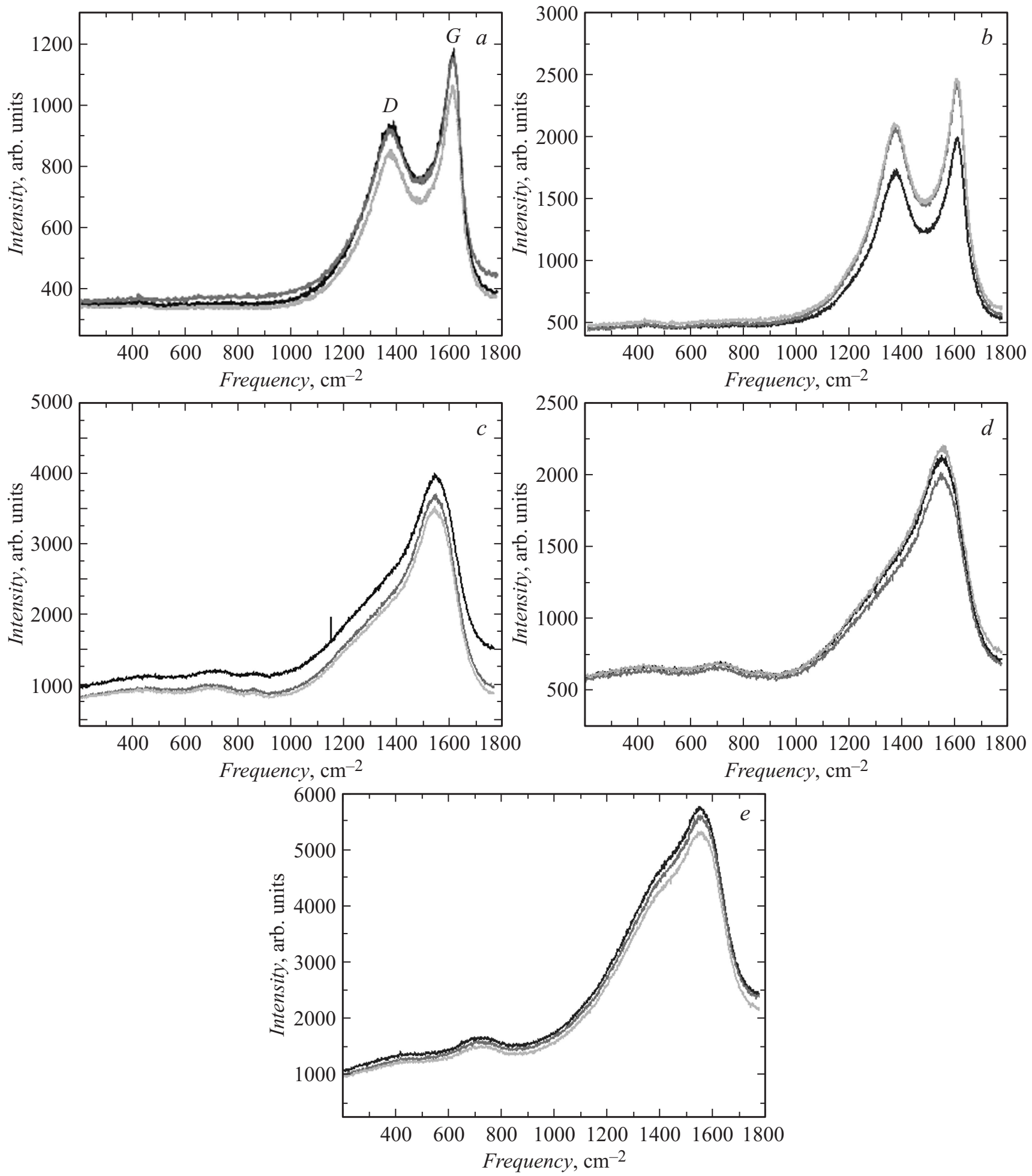

Рис. 2. Спектры рамановского рассеяния алмазографитовых пленочных структур, полученных до (a) и после облучения ионами $\mathrm{N}^{+}$с различными дозами: $1 \cdot 10^{14}(b), 3 \cdot 10^{15}(c), 3 \cdot 10^{16}(d)$ и $3 \cdot 10^{17} \mathrm{~cm}^{-2}(e)$. (Разные кривые на рисунках соответствуют различным точкам поверхности.)

увеличиваются во столько же раз и от дозы облучения практически не зависят. Пороги возбуждения автоэмиссии по сравнению с малой дозой облучения уменьшаются до $22 \mathrm{~V} / \mu \mathrm{m}$. Плотности автоэмиссионных токов сначала уменьшаются при дозе $3 \cdot 10^{15} \mathrm{~cm}^{-2}$ до уровня необлученных покрытий, а затем при дозе $3 \cdot 10^{16} \mathrm{~cm}^{-2}$ увеличиваются по сравнению с ними более чем в 5 раз: с 14.3 до $78.6 \mathrm{~mA} / \mathrm{cm}^{2}$. Скачок максимальных плотностей 


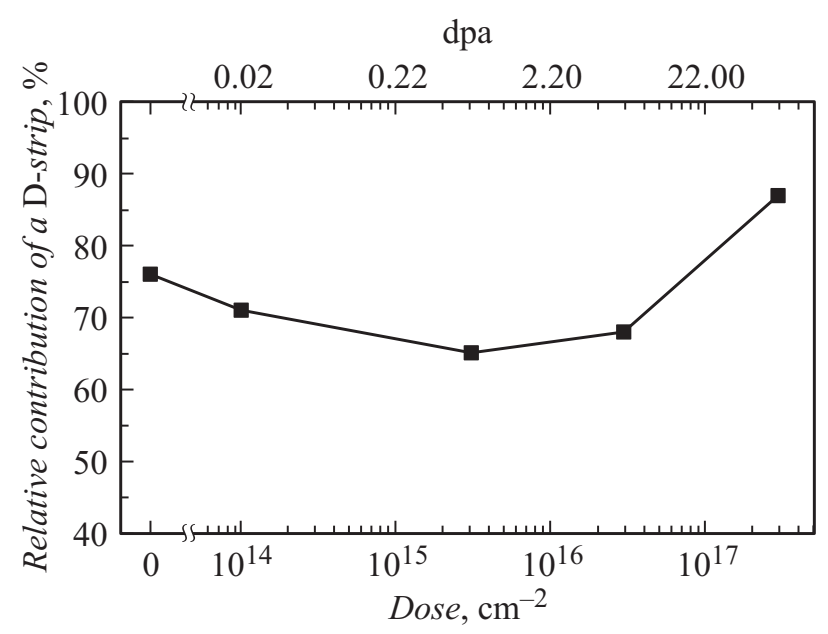

Pис. 3. Зависимость относительной доли $D$-полосы от дозы облучения ионами $\mathrm{N}^{+}$алмазографитовых пленочных структур, полученных при смещении $-300 \mathrm{~V}$.

автоэмиссионного тока при дозе облучения $3 \cdot 10^{16} \mathrm{~cm}^{-2}$ совпадает с экстремумом поверхностной проводимости алмазографитовых структур (рис. $1, c$ ).

При высоких дозах облучения $\left(3 \cdot 10^{17} \mathrm{~cm}^{-2}\right)$ происходит относительное небольшое уменышение высот выступов и порогов возбуждения автоэмиссии при практически неизменной по сравнению со средними дозами поверхностной плотностью. Однако максимальные плотности автоэмиссионных токов уменьшаются по сравнению с дозой $3 \cdot 10^{16} \mathrm{~cm}^{-2}$ больше чем на порядок (до $7.1 \mathrm{~mA} / \mathrm{cm}^{2}$ ). Их уменьшение происходит одновременно с уменьшением поверхностной проводимости, которая по отношению к дозе $3 \cdot 10^{16} \mathrm{~cm}^{-2}$ уменьшается практически в два раза (рис. $1, c$ ).

На рис. 2 приведены спектры рамановского рассеяния алмазографитовых пленочных структур, полученных с использованием конфокальной рамановской микроскопии/спектроскопии до и после облучения ионами $\mathrm{N}^{+}$ с различными дозами. На спектрах исходных пленок и облученных с малыми дозами (рис. 2, $a, b$ ) хорошо различимы пики $G$ и $D$, связанные с $s p^{2}-$ и $s p^{3}$ типами гибридизации соответственно. Облучение с более высокими дозами приводит к уширению пиков за счет разупорядочения микроструктуры и их слиянию, но разложение на гауссовы кривые позволяет во всех случаях определять соотношение между интегральными концентрациями алмазоподобной и графитовой фаз по отношению площади под гауссианой для $s p^{3}$ к суммарной площади обеих гауссиан.

На рис. 3, по данным спектров рамановского рассеяния, приведенных на рис. 2, построена зависимость доли алмазоподобной фазы в нанокомпозитных алмазографитовых структурах, полученных путем разложения на гауссианы, от дозы внедренных ионов азота (количества смещенных атомов). Видно, что влияние облучения на дозовую зависимость доли $s p^{3}$-связей в пленках имеет довольно сложный характер: при малых и средних дозах облучения доля алмазной фазы по сравнению с необлученными образцами пленки уменьшается. Однако при максимальной дозе облучения ее доля, напротив, существенно увеличивается и достигает $87 \%$.

\section{2. Обсуждение результатов}

\section{1. Фазовые превращения в алмазографитовых структурах при ионной имплантации азота}

Использование ионной имплантации азота в алмазографитовые структуры для повышения эксплуатационных свойств автоэмиссионных катодов, изготовленных на их основе, обусловлено потенциальной возможностью регулировать эмиссионные свойства поверхности, а также объемную проводимость материала пленки, которая для обеспечения эффективной электронной автоэмиссии должна быть достаточно высокой. Эмиссионные свойства поверхности зависят от типа химических связей (определяющего работу выхода электронов) и рельефа поверхности (концентраторов поля). Стабильность вакуумных катодов (эмиттеров) в процессе их эксплуатации связана с постепенным распылением поверхности катода ионами при ионизации остаточного газа. Коэффициент распыления углеродных катодов в общем случае зависит от типа связи, и для $s p^{2}$-связей, как показывают эксперименты по ионному распылению, он выше, чем для более прочных $s p^{3}$-связей. Поэтому с точки зрения эмиссионных свойств поверхности и стабильности при эксплуатации преобладание в пленке $s p^{3}$-связей является предпочтительным, тогда как с точки зрения проводимости может иметь место обратная ситуация [5].

При ионном облучении структурно-фазовые превращения (от которых зависит соотношение вклада связей $s p^{3}$ и $s p^{2}$ ) происходят за счет атомных смещений (если не учитывать химическое влияние имплантированных атомов). С ростом массы иона число смещений на единицу пути растет, так что превращения происходят при тем меньшей дозе, чем тяжелее ион. С другой стороны, с ростом массы иона растет коэффициент распыления материала мишени. Следовательно, сильнее будут меняться толщина пленки и рельеф поверхности. Исходя из этого оптимальным представляется выбор ионов азота, которые имеют массу, близкую к массе атомов углерода. Коэффициент аккомодации, характеризующий передачу энергии и импульса атомам углерода от имплантируемых ионов азота, в этом случае близок к единице. Благодаря этому точнее могут быть описаны механизмы структурно-фазовых превращений, которые происходят при ионной имплантации азота в матрицу алмазографитовой структуры пленки. Кроме того, азот как химически активный элемент дает дополнительную потенциальную возможность влияния на свойства материала при больших концентрациях этого элемента 
в матрице как с точки зрения образования новых химических соединений, так и возможного электронного легирования нанокристаллитов алмаза.

Энергия ионов при облучении выбиралась таким образом, чтобы толщина ионно-модифицированного слоя не превышала заданной толщины пленки. При малых дозах, когда можно пренебречь ионным распылением, распределение имплантированных ионов по глубине рассчитывается по программе SRIM [6] (рис. 4). Как видно из рис. $4, a$, при энергии ионов $\mathrm{N}^{+}$, равной $20 \mathrm{keV}$, толщина модифицированного слоя без учета распыления меньше первоначальной толщины пленки. Обеднение радиационными дефектами прилегающей к поверхности области, которые определяют свойства имплантированного слоя при малых дозах облучения, выражено относительно слабо (рис. 4,b). С ростом энергии пробеги ионов возрастают, и глубина модифицированного слоя приближается к толщине пленки, но при этом возрастает ,завал“ концентрации дефектов у поверхности, что является нежелательным фактором.

При больших дозах облучения существенное влияние на профили распределения имплантированной примеси и дефектов оказывает распыление, приводящее к их продвижению вглубь образца и сглаживанию „завала“ у поверхности. Исходя из значения коэффициента аккомодации, близкого к единице, для приближенных оценок можно принять значение коэффициента распыления атомов углерода при облучении ионами азота $S=(1-2)$. Тогда при дозе $\sim 10^{17} \mathrm{~cm}^{-2}$ сдвиг профиля составит 20-40 nm. Такой сдвиг приведет к устранению обедненного дефектами слоя в глубокой части пленки (и к существенному утонению пленки). Исходя из этого энергию ионов $\mathrm{N}^{+} E=20 \mathrm{keV}$ (для исходной толщины пленки $100-150 \mathrm{~nm}$ ) можно считать близкой к оптимальной: при $E<20 \mathrm{keV}$ будет сильнее выражено обеднение в глубокой части пленки для малых доз, а при $E>20 \mathrm{keV}$ возрастет толщина области „завала“ профиля дефектов вблизи поверхности.

С учетом примесных и вакансионных распределений, приведенных на рис. 4, зависимость относительной доли $D$-полосы от дозы облучения ионами $\mathrm{N}^{+}$алмазографитовой матрицы (рис. 3) можно интерпретировать как результат влияния термических пиков на траекториях внедренных ионов, сопровождающихся формированием термоупругих механических напряжений, которые способствуют переходу одной модификации углерода в другую [7]. (Аналогичный эффект ионно-стимулированного перехода $s p^{2} \rightarrow s p^{3}$, но при меньших дозах и меньшей доли $s p^{3}$-связей в исходных пленках, наблюдался в работе [8] в случае облучения алмазоподобных пленок ионами фосфора.) При относительно малых дозах наряду с тенденцией перехода $s p^{2} \rightarrow s p^{3}$ имеет место обратный процесс - графитизация за счет накопления дефектов [9], с одной стороны, и высокой теплопроводности алмазной модификации в нанокомпозитной структуре исходной пленки, которая препятствует быстрому повышению температуры в термических пиках, с другой.
При увеличении дозы растет концентрация дефектов и связей $\mathrm{C}-\mathrm{N}[10,11]$, рассеивающих фононы и тем самым снижающих теплопроводность. В результате увеличивается температура (и связанные с ней термоупругие напряжения) в области интенсивного торможения внедренных ионов, а следовательно, возрастает интенсивность процесса $s p^{2} \rightarrow s p^{3}$. Наибольшее содержание доли алмазоподобной фазы достигается при высоких дозах облучения $\left(3 \cdot 10^{17} \mathrm{~cm}^{-2}\right)$, когда концентрация внедренных атомов азота становится сравнимой с концентрацией атомов углерода в алмазе и графите (в алмазе концентрация атомов углерода равна $1.76 \cdot 10^{23} \mathrm{~cm}^{-3}$, в графите $\left.-1.13 \cdot 10^{23} \mathrm{~cm}^{-3}\right)$.

\section{2. Корреляция фазовых превращений и автоэмиссионных свойств в алмазографитовых структурах}

Как известно, свойства поверхности полупроводниковых и диэлектрических материалов весьма сильно зависят от условий обработки и, в частности, режимов плазмохимического травления или осаждения [4]. Обработка приводит к появлению локализованных на поверхности состояний, которые в зависимости от степени сродства к электрону и дырке, положения уровня Ферми на поверхности могут проявлять себя как донорные или акцепторные ловушки захвата или рекомбинационные ловушки электронно-дырочных пар. При микроволновом плазмохимическом осаждении алмазографитовых пленочных структур с достаточно высоким отрицательным смещением на подложкодержателе $(-300 \mathrm{~V})$ конденсация осуществляется в результате преимущественной бомбардировки поверхности роста положительными ионами. Образующаяся пленочная структура при этом испытывает недостаток в нейтрализующих заряд ионов электронах и находится в термодинамически неравновесном состоянии. Возникающие дефекты и связанные с ними поверхностные состояния приобретают преимущественно акцепторный характер. В связи с недостатком электронов в процессе роста большая их часть не заполнена электронами и они нейтральны.

При малых дозах облучения ионами азота $\left(1 \cdot 10^{14} \mathrm{~cm}^{-2}\right)$ распыление поверхностных атомов алмазографитовой структуры, как показывают экспериментальные результаты (рис. $1, a)$, практически отсутствует. Обеднение радиационными дефектами прилегающей к поверхности области выражено относительно слабо (рис. $4, b)$. Так как при малых дозах именно дефекты, а не внедренная примесь служат основным фактором, определяющим свойства имплантированного слоя, то изменение автоэмиссионных свойств в полученных структурах по сравнению с неимплантированными можно связать только с повышенной дефектностью приповерхностного слоя. Вновь образующиеся при имплантации дефекты структуры в виде смещенных атомов и вакансий увеличивают плотность электронных состояний и вместе с этим интенсивность туннельных 

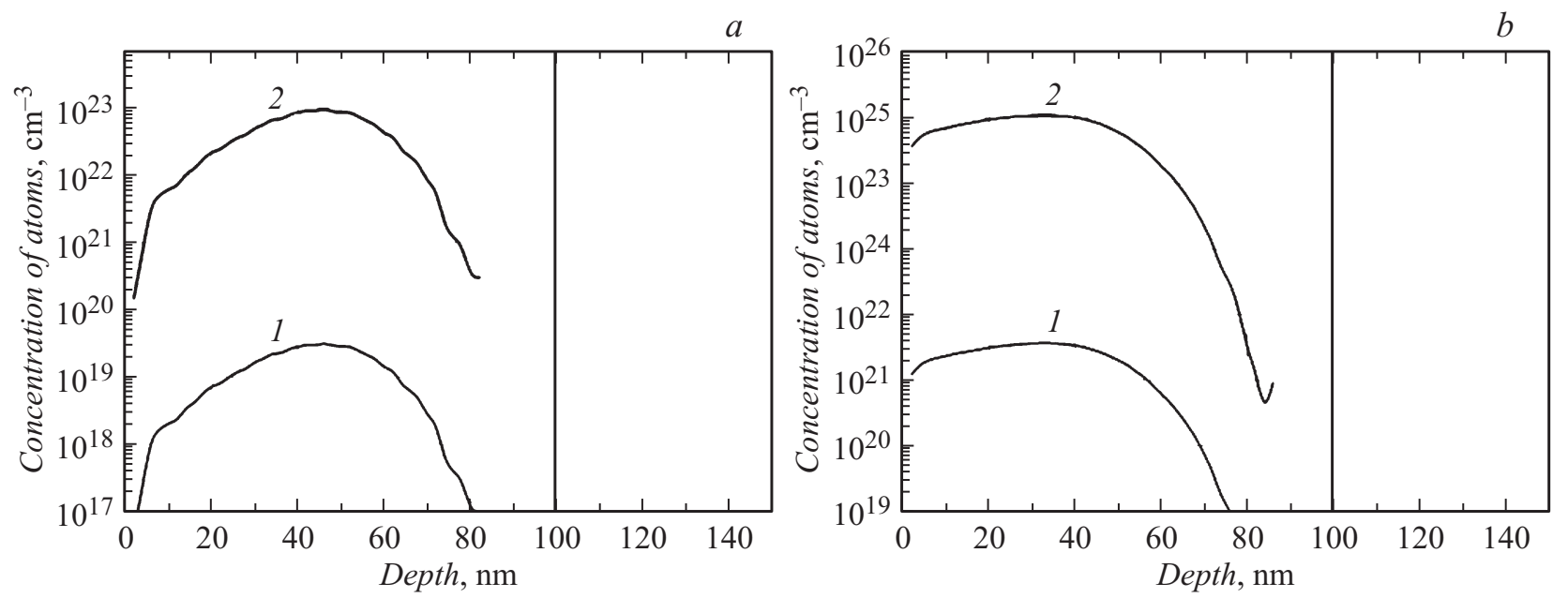

Рис. 4. Расчетные распределения в углероде ионов $\mathrm{N}^{+}(a)$ и смещенных атомов (вакансий) (b) при различных дозах облучения: $1-1 \cdot 10^{14} \mathrm{~cm}^{-2} ; 2-3 \cdot 10^{17} \mathrm{~cm}^{-2}$. Вертикальной линией показана толщина пленки $100 \mathrm{~nm}$.

переходов электронов из приповерхностной области на поверхностные уровни. Благодаря этому увеличиваются при приложении внешнего электрического поля поверхностная проводимость и максимальная плотность автоэмиссионного тока (рис. $1, b, c)$. Вместе с этим акцепторные уровни на поверхности пленочной структуры, являющиеся центрами захвата электронов, по мере их заполнения увеличивают ее отрицательный заряд и, как следствие, работу выхода и потенциальный барьер при автоэмиссии.

При средних и высоких дозах облучения $\left(3 \cdot 10^{15}\right.$ $3 \cdot 10^{17} \mathrm{~cm}^{-2}$ ) необходимо учитывать распыление ионами азота поверхностных атомов алмазографитовой мишени и перестройку морфологии поверхности (рис. 1, a) (как известно, измененная морфология определяется не только видом и энергией ионов, но и длительностью облучения, которая зависит от требуемой величины дозы облучения). При ионной бомбардировке алмазографитовой структуры при наборе средних доз $\left(3 \cdot 10^{15}-3 \cdot 10^{16} \mathrm{~cm}^{-2}\right)$ такая перестройка сопровождается уменьшением высот выступов и повышением их поверхностной плотности. Перестройка поверхности сопровождается распылением термодинамически неравновесного поверхностного слоя алмазографитовой структуры, полученного в результате плазмохимического осаждения в микроволновой плазме паров этанола. Кроме того, увеличение концентрации внедренных ионов азота способствует нейтрализации акцепторных уровней поверхности пленки. Результатом этого является уменьшение величины отрицательного заряда на поверхности алмазографитовой структуры, а также порогов возбуждения автоэмиссии и максимальных плотностей токов до уровней, незначительно отличающихся от характеристик алмазографитовых структур с неимплантированным азотом (рис. $1, b)$.

Резкое увеличение максимальных плотностей автоэмиссионных токов при дозе облучения $3 \cdot 10^{16} \mathrm{~cm}^{-2}$, вероятнее всего, обусловлено легированием алмазных нанокристаллитов донорной примесью азота. Локальные термические пики, возникающие при торможении внедренных ионов, приводят в результате микроотжигов к уменьшению количества дефектов кристаллической решетки ультрадисперсных алмазов, электрической активации внедренных в междуузлия ионов азота и увеличению электропроводности приповерхностного слоя алмазографитовой структуры (рис. 1,b,c). Следствием этого является уменьшение мощностей джоулевых тепловыделений в эмиссионных центрах и увеличение максимальных плотностей автоэмиссионных токов.

При высоких дозах облучения $\left(3 \cdot 10^{17} \mathrm{~cm}^{-2}\right)$ увеличение содержания алмазной фазы в объеме алмазографитовой структуры (рис. 3) резко уменьшает ее электропроводность (рис. 1, c) (алмаз, в котором имеют место $s p^{3}$-связи, обладает на много порядков более высоким удельным сопротивлением по сравнению с графитом $\left(s p^{2}\right.$-связи $\left.)\right)$. Высокое удельное сопротивление затрудняет доступ электронов к поверхности пленки. Увеличение напряженности внешнего электрического поля для увеличения плотностей автоэмиссионных токов приводит к повышенному локальному джоулеву тепловыделению в эмиссионных центрах (выступах). Результатом этого является деструкция морфологии поверхности и снижение максимальных плотностей автоэмиссионных токов.

\section{Заключение}

Радиационная обработка нанокомпозитных алмазографитовых пленочных структур представляется одним из перспективных методов улучшения их автоэмиссионных свойств. Ее преимуществом является возможность относительно независимого управления фазовым составом материала, от которого зависит электронная структура поверхности эмиттера, и последовательное сопротивле- 
ние системы зависящего от объемных свойств покрытия. Облучение ионами с энергиями, при которых пробеги ионов позволяют модифицировать свойства покрытия на разных глубинах, дает возможность более гибко управлять этими свойствами путем выбора вида иона и дозы облучения. Кроме того, выбор надлежащего вида ионов позволяет использовать дополнительный результат модификации, связанный с химическим взаимодействием между внедряемыми ионами и материалом эмиттера, а также донорными и акцепторными свойствами примесных атомов.

Исследование выполнено за счет гранта Российского научного фонда (проект № 16-19-10033).

\section{Список литературы}

[1] Гуляев Ю.В., Абаньшин Н.П., Горфинкель Б.И., Морев С.П., Резчиков А.Ф., Синицын Н.И., Якунин А.Н. // Письма в ЖТФ. 2013. Vol. 39. № 11. С. 63.

[2] Усанов Д.А., ЯФаров Р.К. Методы получения и исследования самоорганизующихся наноструктур на основе кремния и углерода. Саратов: Сарат. гос. ун-т. 2011. 126 с.

[3] Зайцев Н., Горнев Е., Орлов С., Красников А., Свечкарев К., Яфаров Р. // Наноиндустрия. 2011. № 5. С. 36-39.

[4] Яфаров Р.К. Физика СВЧ вакуумно-плазменных нанотехнологий. М.: Физматлит, 2009. 216 с.

[5] Яфаров Р.К. // ЖТФ. 2006. Т. 76. Вып. 1. С. 42.

[6] The Stopping and Range of Ions in Matter / J.F. Ziegler. Режим доступа: http://www.srim.org.

[7] Алмазы в электронной технике: Сб. ст. / Отв. ред. В.Б. Квасков. М.: Энергоатомиздат, 1990. 248 с.

[8] Карасев П.А., Подсвиров О.А., Титов А.И., Карабешкин К.В. и др. // Поверхность. 2014. № 1. С. 49-53.

[9] Vavilov V.S. et al. // Rad. Eff. 1994. Vol. 22. N 2. P. 141-143.

[10] Link F., Baumann H., Markwitz A., Krimmel E.F., Bethge K. // Nucl. Instrum. Method. Phys. Res. B. 1996. Vol. 113. P. 235-238.

[11] Xin H., Lin Ch., Zhu Sh., Zou Sh., Shi X., Zhu H., Hemment P.L.F. // Nucl. Instrum. Method. Phys. Res. B. 1995. Vol. 103. P. 309-312. 